\title{
A longitudinal analysis of moving desires, expectations and actual moving behaviour
}

\section{Abstract}

Residential mobility theory proposes that moves are often preceded by the expression of moving desires and expectations. Much research has investigated how individuals form these pre-move thoughts, with a largely separate literature examining actual mobility. Although a growing number of studies link pre-move thoughts to subsequent moving behaviour, these often do not explicitly distinguish between different types and combinations of pre-move thoughts. Using 1998-2006 British Household Panel Survey (BHPS) data, this study investigates whether moving desires and expectations are empirically distinct pre-move thoughts. Using multinomial regression models we demonstrate that moving desires and expectations have different meanings, and are often held in combination: the factors associated with expecting to move differ depending upon whether the move is also desired (and vice versa). Next, using panel logistic regression models, we show that different desire-expectation combinations have different effects on the probability of subsequent moving behaviour. The study identified two important groups generally overlooked in the literature: those who expect undesired moves and those who desire to move without expecting this to happen.

Key words: moving desires, moving expectations, residential mobility, longitudinal data 


\section{Introduction}

Moving home enables people to adjust their residential location to meet their changing needs and preferences (Clark and Huang, 2004). In the year preceding the 2001 UK census, approximately $10.3 \%$ of Britons changed their place of residence, with the bulk of these individuals moving only over short distances (Bailey and Livingston, 2007). Given the importance of mobility for households and the economy, it is unsurprising that there is a long and rich research tradition exploring how individuals form and act upon decisions to move home. Following Rossi's seminal contribution (Rossi, 1955), studies have generally conceptualised moving as a lengthy and multistep process (Kan, 1999; Kley and Mulder, 2010). Typically, individuals are thought to move following a series of preference formation and move decision making steps (see Brown and Moore, 1970; Kley and Mulder, 2010; Rossi, 1955; Speare et al, 1975 for examples), although this process need not be linear and sequential (Sell and De Jong, 1983). Following such models, researchers have focused their attention on what leads people to desire a move (Buck, 2000; Landale and Guest, 1985; Speare et al, 1975), to intend to move (McHugh, 1984), to plan to move (Kley, 2010; van Arsdol et al, 1968) or to expect to move (Bach and Smith, 1977; Kan, 1999). A largely separate literature has explored actual moves in detail (see Clark and Dieleman, 1996).

There are two major gaps in the literature exploring residential mobility as a process. Firstly, there are conceptual and methodological inconsistencies in the ways researchers have analysed the pre-move preference formation and decision making stages. While many studies take care to explicitly define the type of premove thought under investigation, some lack conceptual and empirical clarity about 
the specific concepts being used. For example, Rossi (1955) treats moving intentions and expectations as equivalents, while Kleinhans (2009) considers moving desires and expectations as examples of a more general 'propensity to move' (see also Morris et al, 1976). This lack of clarity is mainly due to a reliance on secondary survey data, which often includes only one question on pre-move thoughts, focussing on either moving desires, intentions, plans, or expectations. A further consequence of this reliance on secondary surveys is that few studies have examined the differences between various pre-move thoughts, or considered that multiple pre-move thoughts can exist in combination (see Kley, 2010; Kley and Mulder, 2010; Sell and De Jong, 1983 for exceptions). This lack of conceptual and methodological clarity hinders the empirical testing of mobility models, as different pre-move thoughts are likely to be distinct concepts produced by specific sets of factors (see Kley, 2010). In addition, different combinations of pre-move thoughts are likely to reflect different levels of commitment to mobility.

A second gap in the literature concerns the empirical testing of theoretical mobility models. Many papers have focused solely on individuals' stated housing preferences or pre-move thoughts, without exploring their actual moving behaviour (see Molin et al, 1996; Sirgy et al, 2005). Recent longitudinal research is helping to address this deficiency, by investigating the mobility behaviour of individuals who had, or had not expressed pre-move thoughts (Buck, 2000; Clark and Davies Withers, 2007; De Groot et al, 2011; Ferreira and Taylor, 2009; Kan, 1999; Kley and Mulder, 2010; Lu, 1999a; Lu, 1998). However, such studies typically only link the expression of one pre-move thought to actual moving behaviour, potentially obscuring variation between individuals in the likelihood of their thoughts being 
realised. This is because many panel surveys only ask respondents one question about whether they are thinking of moving.

The above observations lead to the formation of three working hypotheses. Firstly, we hypothesise that moving desires and expectations are different and distinct pre-move thoughts, influenced by different predictor variables. It is anticipated that moving desires are more strongly influenced by subjective evaluations of dwelling and neighbourhood quality than moving expectations, as moving expectations may also be the outcome of sudden life events rather than gradual increases in dissatisfaction. In addition, expressing a desire to move may be less constrained by household and macro-contextual circumstances (see Lu, 1998; Sell and De Jong, 1983).

Secondly, it is hypothesised that moving desires and expectations can be held in distinct combinations. The characteristics of those desiring but not expecting to move are likely to differ from those who both desire and expect to move, with limited access to resources inhibiting some individuals from expecting to be able to act upon their moving desires. Uncovering this heterogeneity will enable us to develop our understanding of the different decision making pathways people follow when deliberating a move. Analysing desires and expectations in combination will also shed light on the factors inhibiting individuals from acting upon their moving desires, as well as developing our understanding of why people expect undesired moves.

Thirdly, we anticipate that the combination of moving desires and expectations expressed affects the likelihood of subsequently moving. It is hypothesised that the likelihood of realising a moving desire is increased if a move is also expected. In this light it is important to distinguish between desires and expectations that lead to a move, and moving desires which do not lead to a move 
due to a lack of expected opportunities to realise this desire. We anticipate that individuals with lower incomes are less likely to expect to be able to act upon their moving desires, potentially 'trapping' them in less desirable dwellings and neighbourhoods if they are subsequently unable to actually move. We argue that revealed preference techniques may therefore be insufficient to fully understand housing preferences, as certain individuals may be constrained from realising their underlying desires through mobility (see Molin et al, 1996).

This paper contributes to the mobility literature in three empirically innovative ways. First, it explores whether moving desires and expectations are empirically distinct concepts. Second, it analyses who is most likely to express different moving desire-expectation combinations. Finally, the paper investigates the links between moving desire-expectation combinations and subsequent mobility behaviour. No previous study has investigated these issues in combination, and the outcomes will contribute to a refinement of theories of mobility. The study uses 8 waves of British Household Panel Survey (BHPS) data and panel regression models.

\section{Literature review}

Much of our conceptual understanding of how individuals make moving decisions has focused upon mobility as an adjustment response to rising housing stress, which creates disequilibrium between the current and a desired housing situation. Stressthreshold models propose that people move in response to this disequilibirum, changing residence in order to improve the utility they derive from their housing consumption and hence reduce their housing stress (Brown and Moore, 1970; De 
Jong and Fawcett, 1981; Wolpert, 1965). Speare et al (1975; Speare, 1974) introduced the concept of residential satisfaction as a mediating construct between the factors altering place utility calculations and the formation of a moving desire. In Speare's model, individuals initiate the moving process when dissatisfaction with their current dwelling passes an internally defined threshold. This dissatisfaction can arise due to life events, such as household expansion and a shortage of dwelling space or the possibility of accepting a better job elsewhere (see Speare et al, 1975). As mobility is a response to housing stress, moving should therefore enable individuals to improve their housing and neighbourhood satisfaction (see Lu, 1999b).

A central feature of such models is that moving is a process and not a discrete event. Moves made as a response to housing stress are typically thought to be preceded by some form of preference formation, deliberation and destination choice processes, often conceptualised as comprising a series of 'steps' (eg. Brown and Moore, 1970; Kley, 2010; Rossi, 1955; Speare et al, 1975). Different pre-move thoughts are expressed at each of these stages (see Kley, 2010). The initial reaction to rising housing stress and dissatisfaction is typically the expression of a desire to move (Rossi, 1955). Expressing this initial moving desire indicates that an individual perceives that moving would improve their wellbeing. Although cognitive dissonance reduction behaviour may inhibit an individual from expressing a desire to move when moving is deemed impossible, in general, expressing a moving desire involves far less consideration of feasibility than expressing moving intentions, plans or expectations (Lu, 1998). Micro-level restrictions (such as having a low income) and macro-contextual constraints (such as living in a tight local housing market) should therefore have relatively weak effects on moving desires, but progressively stronger 
effects on moving intentions, expectations and actual moving behaviour (van Ham and Feijten, 2008).

Much prior research confirms that dissatisfaction with dwelling or neighbourhood conditions is a key motivation for individuals to desire to move (Deane, 1990; Landale and Guest, 1985; Speare et al, 1975). This dissatisfaction may be a consequence of rising housing stress, or alternatively may arise as a consequence of social mobility aspirations (Speare, 1974). Individuals living in housing which does not meet socially constructed norms may feel dissatisfied with their housing situation, stimulating a desire to move to a dwelling and neighbourhood which meet these cultural standards (Morris et al, 1976; Morris and Winter, 1975). Although housing norms vary with stage in the life course and social group, generally in Western societies such norms prioritise single family (detached) properties, homeownership and surplus dwelling space.

Over time, moving desires can strengthen and stimulate the expression of moving intentions and finally expectations (Rossi, 1955; Sell and De Jong, 1983). Individuals expecting to move have assessed the move as more likely than not to occur in the specified period. Expectations of moving should therefore closely predict actual moves, although previous work suggests that the link is weaker than might be anticipated (Kan, 1999). Moving from solely desiring to desiring and expecting to move requires the individual to judge that moving is possible, indicating a high level of commitment to mobility (see De Groot et al, 2011; Sell and De Jong, 1983). This is compatible with the theory of planned behaviour (Ajzen, 1991; De Jong, 2001; Kley, 2010). While all individuals who desire to move anticipate that moving will enable them to attain valued goals, whether an expectation is also expressed may depend upon whether the individual also perceives they are in control of the mobility process. 
Those desiring but not expecting to move thus may perceive that they lack control, as micro-level restrictions (such as low incomes or caring responsibilities) or macrolevel constraints (such as a lack of appropriate housing vacancies) are judged to be insurmountable.

The model of the moving decision process outlined so far focuses on moving as a volitional response to housing stress, triggered primarily by dissatisfaction. Not all decision making may however follow this linear progression. While housing stress may increase gradually over time, events in the life careers of household members can rapidly increase housing stress levels or directly trigger undesired moves (Clark and Ledwith, 2006; Clark and Davies Withers, 1999; Mulder and Hooimeijer, 1999). Events in the labour force career such as getting a job, becoming unemployed or retiring, as well as household events such as union formation, dissolution and childbirth have been shown to strongly affect moving behaviour (eg. Böheim and Taylor, 2002; Clark and Davies Withers, 1999; Feijten and van Ham, 2010; Flowerdew and Al-Hamad, 2004). Unless anticipated, such moves are unlikely to occur following a lengthy and sequential decision making process, but instead may have been preceded by the sudden expression of an expectation of moving, even if this was not desired. Expressing an undesired expectation of moving may indicate that a person anticipates having to move to respond to changing circumstances, such as unemployment or union dissolution, rather than to pursue valued goals.

To better understand this non-linearity of the decision making process, considering the combination of pre-move thoughts expressed may be valuable. While many individuals may desire to move, only those who perceive that they are also able to overcome the restrictions and constraints impeding a possible adjustment move are likely to simultaneously expect to relocate. Equally, while 
desiring and expecting to move may be the outcome of a lengthy period of decision making motivated by dissatisfaction, expressing a moving expectation but no moving desire may indicate that life events are disrupting the individual's preferred housing career. Dissatisfaction with dwelling or neighbourhood conditions is therefore likely to be strongly associated with moving expectations only when these are expressed in conjunction with a moving desire. Investigating whether individuals express premove thoughts in combination could therefore help to reconcile the stress and event triggers of moving into one conceptual model.

While a growing number of longitudinal studies link pre-move thoughts to subsequent moving behaviour (eg. Buck, 2000; De Groot et al, 2011; Duncan and Newman, 1976; Ferreira and Taylor, 2009; Kan, 1999; Lu, 1999a; Lu, 1998), few have investigated whether the non-linearity of the mobility process means that the combination of pre-move thoughts expressed alters subsequent behaviour (see Kley, 2010; Kley and Mulder, 2010 for exceptions). This is often due to data constraints, as panel surveys typically gather information about only one type of pre-move thought. Prior research by Sell and De Jong (1983) demonstrates the value of considering desires and expectations in combinations, as only approximately $56 \%$ of movers in their study exactly followed the sequential decision making process. We might therefore anticipate the likelihood of a desire to move being realised to partially depend upon whether or not the move is also expected. Those desiring but not expecting a move may be unlikely to move, perhaps as the lack of resources inhibiting them from perceiving that moving will be possible also prevents them actually moving. Those desiring and expecting a move may be much more likely to actually move, as they assess that they can overcome any restrictions or constraints. 
Those expecting undesired moves are likely to fall between these extremes, as such individuals may strive to avoid having to move.

Analysing moving desires and expectations in combinations also enables us to develop our understanding of the consequences of mobility for individual wellbeing. The consequences of making an expected move are likely to be influenced by whether or not the move was also desired. While some people may make expected but undesired moves as they accept these are necessary to access other valued opportunities (such as career progression), for others, undesired expected moves could have negative effects on their quality of life. In contrast, making a desired and expected move is likely to have a positive impact upon individual wellbeing.

\section{Data and methods}

\section{Dataset and selection}

This study made use of the British Household Panel Survey (BHPS). The BHPS is a panel survey comprising a sample of 10,300 individuals (from 5,500 households), selected from across the UK in 1991 and re-interviewed each subsequent year (Berthoud, 2000; Taylor et al, 2010). The sample is representative of the UK population and was boosted in 1999 and 2001 with additional households from Scotland, Wales and Northern Ireland. Each year, respondents were asked to answer wide ranging questions across a host of topics. A crucial advantage of the BHPS is its low attrition rate, although moving individuals are known to be more likely to drop out than non-movers (as with most panel surveys). Buck (2000) 
showed that the BHPS is ideal for studying mobility behaviour, as we typically know whether individuals have moved even if they were not re-interviewed.

This study made use of a panel of 8 waves of BHPS data covering the period 1998-2006, with wave 11 (2001) excluded. Analysis was restricted to these waves as information on key variables was not collected during other survey sweeps. Pre-1998 waves of the survey were excluded because information on moving expectations was not gathered in these years. The dataset was transformed into person-year format prior to analysis. Person-years in which the respondent was a dependent child or lived in an institution were removed, as these individuals do not have independent housing careers. Cases missing values on key dependent or control variables (such as moving desires, expectations or housing tenure) were also removed, as were observations where the respondent's moving status between waves $t$ and $t+1$ was unknown.

One member of each household was then randomly selected for analysis, as there is likely to be correlation in pre-move thoughts and moving behaviour between household members. Exceptions were made for person-years in which the respondent lived with multiple unrelated adults, with all such person-years included (as these individuals are likely to have largely independent housing careers). Only respondents defined as 'decision-makers' were eligible for selection, as the views of these individuals are likely to be the most important determinants of actual household mobility. Household decision-makers were identified as the owners or renters of the dwelling and their partners, with household heads and their partners coded as decision-makers if ownership or rental information was missing. After a decision-maker was randomly selected at the household's wave of entry, this respondent was followed for as long as they remained a decision-maker. In the event 
of a household losing its selected individual (due to attrition, non-response or household composition changes), a new decision-maker was randomly selected and tracked. Following these procedures, the final sample contained 63,083 personyears provided by 14,506 respondents.

\section{Methods}

The first set of analyses explored the existence of moving desire-expectation combinations using a multinomial logistic regression model, with standard errors adjusted for the clustering of observations within respondents (Wooldridge, 2002). This necessitated the creation of a four-way categorical dependent variable indicating the combination of dichotomous moving desires and expectations the respondent expressed at each wave. Moving desires were measured by the answer to the following survey question: 'If you could choose, would you stay here in your present home or would you prefer to move somewhere else?'. Moving expectations were measured by the response given to the question: 'Do you expect you will move in the coming year?. Those person-years in which the respondent answered that they 'did not know' whether they desired or expected a move were classified as having no moving desire or moving expectation respectively. This is because not desiring or expecting to move can be thought of as the default response, with those respondents not clearly expressing a moving preference or expectation most likely to have not given moving much thought. Further analyses (not shown here) reveal that removing these person-years has little effect on the modelling results.

From the literature review, it was anticipated that subjective evaluations of housing and neighbourhood quality were likely to have important links to pre-move thoughts and moving behaviour. A dichotomous variable indicating whether an 
individual liked their neighbourhood was constructed from the answer given to the following survey question: 'Overall, do you like living in this neighbourhood?'. A variable indicating whether the individual was satisfied with their dwelling was constructed from the answer to the survey question: 'How dissatisfied or satisfied are you with your house/flat?'. To ensure comparability, although respondents replied to this question using a 7-point Likert scale, responses were dichotomised (with neutral responses coded as dissatisfied as satisfaction is anticipated to be the default response). Various independent variables identified by previous research as being strongly linked to moving behaviours were also included in the model (see Table 1). The main hypothesised effects of these variables on moving desire-expectation combinations are presented in Table 2.

\footnotetext{
${ }^{* * *}$ Table 1 about here ${ }^{* * *}$

***Table 2 about here ${ }^{\star \star *}$
}

The second set of analyses modelled the likelihood of an actual move over any distance occurring between waves $t$ and $t+1$, with the respondent's wave $t$ moving desire-expectation combination included as an independent variable. A host of lagged control variables were also included (see Table 1 for details and Table 2 for hypothesised effects). The status transition variables included in these models capture whether an event (such as a union formation) occurred between the expression of the desire-expectation and the move response (rather than before the desire-expectation as in the multinomial model). A one-year interval between the expression of the moving desire-expectation combination and the observation of actual moving behaviour was chosen for two reasons. Firstly, the moving expectation 
survey question explicitly elicited the respondent's expectation of moving within a one year period. Secondly, linking moving desire-expectation combinations to actual moves over greater time gaps would necessitate ignoring the respondent's preferences and expectations at the intervening waves. To model mobility, panel logistic regression models were used (Hsiao, 2003). These models take into account that person-years are nested within individuals and that there may be individual specific variance in moving behaviour.

\section{Analysis}

Given the well known associations between age and mobility propensity (Clark and Dieleman, 1996), it is surprising that the expression of moving desires and expectations across the life course has not been documented. Figure 1 provides a graph plotting the percentage of cases in each age category where the respondent expressed one of the moving desire-expectation combinations or made an actual move. The familiar pattern of declining actual mobility with age is evident, with mobility rates highest amongst young adults, before dropping rapidly and levelling off in the early 40s. Rates of desiring and expecting a move also drop with age (albeit less sharply), closely tracking the actual mobility rate throughout middle and old age. Unsurprisingly, the proportion of cases where no desire or expectation to move was expressed increases steadily with age. Expressing an expectation of making an undesired move is largely a feature of young adulthood, presumably due to the dynamic life careers and often unstable housing situations of young people. Interestingly, the proportion of cases where the respondent desired but did not 
expect to move is particularly high for middle-aged individuals (between 30 and 60). For these age groups, the large difference between the proportion of people desiring but not expecting to move and the much lower proportion of people who actually move suggests that many people may be unable to act upon their moving desires.

\footnotetext{
${ }^{\star * *}$ Figure 1 about here ${ }^{\star * *}$
}

\section{Expressing moving desires and expectations}

In order to begin to test the first two hypotheses, Table 3 presents the bivariate relationships between housing satisfaction, (dis)liking the neighbourhood and moving desire-expectation combinations. The column totals suggest that moving desires and expectations are distinct concepts, as individuals desire a move in far more personyears than they expect a move. Considering combinations of desires and expectations also appears important. Desiring but not expecting a move $(21.32 \%$ of person years) is much more common than desiring and expecting a move $(7.74 \%$ of person years), while expecting an undesired move $(3.46 \%$ of person years) is the least common combination. The results show that in cases where the respondent reported satisfaction with their dwelling or liking their neighbourhood, respondents also typically reported no desire or expectation of moving. Dissatisfaction with the dwelling or particularly disliking the neighbourhood is closely associated with moving desires, but much more weakly associated with expecting an undesired move. This shows that subjective evaluations of dwelling and neighbourhood quality have conditional effects on moving expectations. Individuals who are unhappy with their current housing situation appear likely to expect a move only if one is also desired. 
It is striking that $62 \%$ of those who dislike their neighbourhood desire but do not expect to move, while only $39 \%$ of those who are dissatisfied with their dwelling report this combination. This disparity is possibly partially due to the difference in the phrasing of the survey questions, with 'disliking' representing a much stronger negative sentiment than 'dissatisfaction'. However it is also possible that people living in the least desirable areas lack the opportunity to move and hence consistently report disliking their neighbourhood and desiring a move. While households can ameliorate dwelling dissatisfaction through in situ improvement (perhaps through constructing an extension or paying for repairs, renovation or redecoration), the neighbourhood context is largely outside the control of individuals and hence can only be improved through mobility.

\section{${ }^{* \star *}$ Table 3 about here ${ }^{* * *}$}

Table 4 presents the results of a multinomial regression model analysing the factors associated with expressing different moving desire-expectation combinations. The reference category is having no desire or expectation of moving. Hausman and Small-Hsiao tests of the Independence of Irrelevant Alternatives assumption indicate that this assumption is not violated (results not shown). The pseudo $r^{2}$ value indicates that the model explains $19 \%$ of the variance in expressed moving desireexpectation combinations. This implies that unobserved individual factors such as anticipated life events, personal relationships with family and friends or perceived career opportunities have a strong influence on the expression of pre-move thoughts. Overall, the modelling results lend support to the idea that moving desires and expectations are different pre-move thoughts held in distinct combinations. 
Housing dissatisfaction or disliking the neighbourhood are strongly associated with desiring or desiring and expecting a move. These variables have much weaker (and less significant) effects on expecting an undesired move, indicating that expecting an undesired move is rarely a result of perceived deficiencies with the dwelling or neighbourhood.

\section{${ }^{\star \star *}$ Table 4 about here ${ }^{\star * *}$}

As people get older, they are more likely to express a desire without expecting a move, and less likely to expect any sort of move. This pattern reflects the findings from Figure 1. Women are less likely than men to express any of the moving desireexpectation combinations compared to not desiring or expecting. The only significant effect for ethnicity shows that ethnic minorities are more likely than others to desire but not expect to move. This indicates that ethnic minorities perceive themselves as less able to realise their housing preferences.

The effects of a change of partner status are different for each moving desireexpectation combination. Those who remained single over the last year are the least likely to desire a move without expecting one, although they are highly likely to expect an undesired move or to expect a desired move. Forming partnerships seems to principally affect moving desires. In contrast, ending a partnership has a large positive impact on the propensity to expect a desired or undesired move, as individuals seek to adjust their housing consumption to meet their changed circumstances following widowhood or union dissolution. These effects suggest that life events have greater impacts on moving expectations than on moving desires. This indicates that moving decisions do not always follow a linear path and that 
dissatisfaction does not completely mediate between changing household circumstances and the expression of pre-move thoughts.

The effects of various other independent variables also generally support the conjecture that moving desires and expectations are held in distinct combinations. Almost all of the children dummies are negative and significant across the model. This implies that having any number of children reduces all thoughts of moving, perhaps because people have already moved prior to childbirth in anticipation of their changing housing needs. Education level was found to be most strongly linked to desiring and expecting a move, with the highly educated most likely to express this combination. High levels of education are also associated with expecting an undesired move. This may be because career progression in highly skilled occupations often requires spatial flexibility (van Ham et al, 2001). Unexpectedly, we find that those with higher levels of education are also more likely to desire but not expect to move than those with very low levels of education. This may be because higher levels of education increase employment opportunities, access to information and widen the awareness spaces of individuals (Flowerdew and Al-Hamad, 2004). This could make more educated individuals increasingly likely to think about moving and hence express weak moving desires, even when moving is not seriously being considered.

Changes in employment status appear associated with desire-expectation combinations. Individuals who become unemployed are more likely to expect to move, while becoming economically inactive reduces the propensity to desire but not expect to move and increases the propensity to expect to make a desired move. This many be because the loss of workplace ties is perceived to grant people greater freedom to move. Household income has a negative effect only on the combination 
desiring but not expecting a move, presumably because those with higher incomes have either already selected themselves into more desirable locations or because they anticipate being able to quickly act upon their moving desires. Housing tenure is strongly associated with pre-move thoughts. Social renters appear to be particularly disadvantaged, as they are more likely to desire but not expect a move and less likely to desire and expect a move. In contrast, private renting is most strongly associated with expecting to move. Roomstress is positively associated with expressing all desire-expectation combinations, while longer durations of stay in the current dwelling appear to predominantly have significant positive effects on moving desires.

To summarize, the results in Table 4 show that those who are unhappy with their home or neighbourhood, with lower incomes and living with high levels of

roomstress are highly likely to desire but not expect a move. Individuals with dynamic life courses, such as the young and highly educated, private renters and those experiencing union dissolution or widowhood events are much more likely to expect an undesired move. Unsurprisingly, these individuals are also likely to desire and expect a move. However, housing stress also appears to be a much stronger factor here, as being unhappy with dwelling or neighbourhood conditions is very strongly associated with desiring and expecting to move.

\section{Moving desire-expectation combinations and subsequent mobility}

Next we explore how different moving desire-expectation combinations affect subsequent moving behaviour. Considering combinations may be important, as linking only one pre-move thought to actual moving behaviour may ignore substantial differences between individuals in the likelihood of this thought being realised. Table 
5 presents bivariate associations between moving desire-expectation combinations and actual moves over the subsequent year. The patterns found persist when the gap between expressed desire-expectation combinations and actual moves is extended from 1 to 2 or 3 year intervals, although the absolute numbers moving in each category increases and sample size drops (results not shown).

\section{${ }^{\star \star *}$ Table 5 about here ${ }^{\star * *}$}

Moves occur in $10.57 \%$ of cases (see Buck, 2000 for similar findings using the BHPS), although this rate varies greatly depending upon the prior desire-expectation combination expressed. Respondents reporting no desire or expectation of moving are unlikely to subsequently actually move, with those desiring but not expecting a move only slightly more likely to do so. Expectations appear to predict moves much more closely, particularly if accompanied by a desire. This confirms that desires are expressed with much less consideration of feasibility than expectations. Importantly, even where moves are desired and expected an actual move is subsequently only made in $54.86 \%$ of cases. This is probably because executing the move was more difficult than anticipated or because the expected move was postponed or abandoned. Considering moving desire-expectation combinations appears to enhance the precision of longitudinal research analysing the likelihood of pre-move thoughts translating into actual moves, as desires are likely to be realised only if accompanied by an expectation.

Table 6 presents the results of two panel logistic regression models analysing the likelihood of an actual move occurring in the year following the expression of moving desire-expectation combinations. The fit of the models indicates that moving 
behaviour is also affected by unobserved factors, such as unknown changes in household circumstances or in individual pre-move thoughts between $t$ and $t+1$. Model 1 presents a basic model of actual moves, including a number of control variables known to be strongly associated with mobility. In contrast to the multinomial model in Table 4, in these models the status transition variables capture events in the respondents' life careers between the expression of the desire-expectation combination and the possible move response. This is because the results in Table 4 show that the effects of life events occurring prior to the expression of the desireexpectation combination will be channelled through these pre-move thoughts. In general, the control variables have the anticipated effects: with increasing age, individuals are less likely to move; union formation and dissolution/widowhood events strongly increase mobility; having children decreases mobility (unless the number of children increases); higher levels of education and changes in economic status are associated with moving; higher levels of income facilitate mobility; private renters are more mobile than homeowners; experiencing a deficiency of space increases mobility; longer durations at the same address and housing satisfaction or liking the neighbourhood lead to a lower likelihood of subsequently moving.

***Table 6 about here ${ }^{\star * *}$

Model 2 presents an identical model but with prior moving desire-expectations added, which greatly improves the model fit compared to Model 1 . Those desiring a move without an expectation are somewhat more likely to subsequently move than those with no desire or expectation of moving. Expecting to move appears to be much more strongly linked to actual moves, as individuals expecting to move are 
highly likely to do so, particularly if this expected move is also desired. To accurately model the links between moving desires or expectations and actual moves, it is beneficial to consider the two in combination. This is important as many studies only include one type of pre-move thought. The control variable parameters change only slightly when desire-expectations are added, although most of the socio-economic variables (except having a high level of education or exiting the labour force) and disliking the neighbourhood become insignificant. This indicates that desires and expectations mediate the direct effects these factors have on mobility. Interestingly, the private rental coefficient remains strongly positive and significant in Model 2. This suggests that there is much unwanted and unexpected mobility in the private rental sector, perhaps due to a lack of security of tenure.

\section{Conclusions}

This paper was motivated by concerns that the mobility literature does not always empirically distinguish various pre-move thoughts and their associations with subsequent moving behaviour. We hypothesised that moving desires and expectations are distinct pre-move thoughts which are influenced differently by predictor variables. This is supported by the results, which demonstrate that dwelling dissatisfaction or disliking the neighbourhood are much more strongly associated with desiring rather than expecting to move. The findings also support the second hypothesis that moving desires and expectations are held in combinations. While desiring to move is strongly associated with dwelling dissatisfaction or disliking the neighbourhood, mainly spatially flexible individuals such as young, highly educated 
private renters expect to be able to realise this desire. Older individuals, those with lower incomes and social renters tend to express a desire to move without an expectation that this will be quickly accomplished. This resonates with the theory of planned behaviour (Ajzen, 1991), as these individuals may perceive that they lack the control necessary to escape undesirable dwellings and neighbourhoods, potentially harming their quality of life. Equally, life events such as union formation and dissolution are associated with moving expectations, strongly affecting moving desires only if these are held in conjunction with an expectation. Taken together, these findings emphasise that considering combinations of pre-move thoughts is important for our understanding of the mobility process, as decision making is often non-linear (see Sell and De Jong, 1983).

This study also aimed to investigate how moving desire-expectation combinations affect subsequent moving behaviour. In the BHPS, information on moving desires, expectations and actual moving behaviour is only available at one year intervals. Given this spacing of observation intervals, it is possible that some individuals with a desire to move subsequently stopped desiring the move before their next interview. This may partially explain why the likelihood of actually moving when the move is only desired is relatively low. It is however possible that this abandonment of a desire may be a form of cognitive dissonance reduction, with respondents abandoning unattainable desires to safeguard their mental wellbeing. In addition, others may have quickly formed and acted upon a moving desire within the year, thereby appearing to make an unwanted move.

Despite these potential methodological shortcomings, the results provide support for the third hypothesis, showing that the combination of moving desires and expectations expressed affects the likelihood of an individual making a subsequent 
move. While only desiring a move is associated with a somewhat higher propensity to actually move, the likelihood of actually moving is much greater if the move is also expected. This demonstrates that differences between individuals expressing the same pre-move thought can have a substantial impact on their subsequent behaviour. These differences are obscured if only one pre-move thought is linked to subsequent mobility. One insight gained from the analysis of desire-expectation combinations is that those individuals who do not expect to be able to make a desired move (typically social renters and those with lower incomes) are also unlikely to actually move. This indicates that neighbourhood stratification by socioeconomic status may be an outcome of unfulfilled moving desires, as poorer residents may be unable to realise their desires to move out of less desirable places. This has implications for studies relying upon revealed preference approaches to investigate housing choices, as a selective group of individuals cannot realise their underlying preferences. It is important to note that while desiring and expecting a move is strongly associated with subsequent mobility, $45 \%$ of individuals reporting this combination do not move over the next year. This suggests that for many people, desires and expectations may be easily formed, but then abandoned, or behavioural responses postponed. Alternatively, it is possible that people are not able to accurately assess the feasibility of actually moving.

This study contributed to the mobility literature both empirically and conceptually. Empirically, considering combinations of pre-move thoughts has identified hitherto ignored variation between people expressing similar moving desires and expectations. This enables us to better conceptualise how different types of individuals make moving decisions, both to resolve gradual increases in housing stress and as a response to life events. The study has then explored how 
moving desires and expectations combine to affect subsequent actual mobility. These findings are of relevance for future longitudinal research. While it is undoubtedly valuable to link single pre-move thoughts to subsequent moving behaviour, we have shown that it may be apt to consider pre-move thoughts as combinations. By revealing substantial variations between individuals who seem to share the same thoughts about moving, such an approach enables us to create more precise models of moving behaviour.

The results also have conceptual implications. As desires and expectations are formed in different ways and have different implications for mobility, future studies need to be precise in their use of terms and take care to link these accurately to the empirical material being discussed. By considering pre-move thoughts as combinations we can better understand how life events may alter and disrupt linear decision making processes. This will enable us to enhance our conceptual decision making models, to more fully acknowledge the importance of housing stress and life events as triggers of mobility.

\section{Disclaimer}

The data used in this study were made available through the ESRC Data Archive. The data were originally collected by the ESRC Research Centre on Micro-Social Change at the University of Essex (now incorporated within the Institute for Social and Economic Research). Neither the original collectors of the data nor the Archive bear any responsibility for the analyses or interpretations presented here. 


\section{References}

Ajzen I, (1991) "The theory of planned behavior" Organizational Behavior and Human Decision Processes 50 179-211

Bach R L, Smith J, 1977, "Community satisfaction, expectations of moving, and migration" Demography 14 147-167

Bailey N, Livingston M, 2007 Population turnover and area deprivation (Policy Press, Bristol)

Berthoud R, 2000, "Introduction: the dynamics of social change", in Seven Years in the Lives of British Families Eds R Berthoud, J Gershuny (Policy Press, Bristol) pp 120

Böheim R, Taylor M, 2002, "Tied down or room to move? Investigating the relationships between housing tenure, employment status and residential mobility in Britain" Scottish Journal of Political Economy 49 369-392

Brown L A, Moore E G, 1970, "The intra-urban migration process: A perspective" Geografiska Annaler. Series B, Human Geography 52 1-13

Buck N, 2000, "Using panel surveys to study migration and residential mobility", in Researching Social and Economic Change: The Uses of Household Panel Studies Ed. D Rose (Routledge, London) pp 250-27 
Clark, W A V, Dieleman F, 1996 Households and Housing: Choice and Outcomes in the Housing Market (Centre for Urban Policy Research, New Brunswick)

Clark W A V, Davies Withers S, 1999, "Changing jobs and changing houses: mobility outcomes of employment transitions" Journal of Regional Science 39 653-673

Clark W A V, Huang Y, 2004, "Linking migration and mobility: Individual and contextual effects in housing markets in the UK" Regional Studies 38 617-628

Clark W A V, Ledwith V, 2006, "Mobility, housing stress, and neighborhood contexts: evidence from Los Angeles" Environment and Planning A 38 1077-1093

Clark W A V, Davies Withers S, 2007, "Family migration and mobility sequences in the United States: spatial mobility in the context of the life course" Demographic Research 17 591-622

De Groot C, Mulder C H, Das M, Manting D, 2011, "Life events and the gap between intention to move and actual mobility" Environment and Planning A 43 48-66

De Jong G, Fawcett J, 1981, "Motivations for migration: An assessment and a valueexpectancy research model", in Migration Decision Making: Multidisciplinary Approaches to Microlevel Studies in Developed and Developing Countries Eds G De Jong and R W Gardner (Pergamon, Oxford) pp 13-58 
De Jong G, 2001, "Expectations, gender, and norms in migration decision-making" Population Studies 54 307-319

Deane G D, 1990, "Mobility and adjustments: paths to the resolution of residential stress" Demography 27 65-79

Duncan G J, Newman S J, 1976, "Expected and actual residential mobility" Journal of the American Planning Association 42 174-186

Feijten P, van Ham M, 2010, "The impact of splitting up and divorce on housing careers in the UK" Housing Studies 25 483-507

Ferreira P, Taylor M, 2009, "Residential mobility, mobility preferences and psychological health", in Changing Relationships Eds M Brynin and J Ermisch (Routledge, Oxford) pp 168-189

Flowerdew R, Al-Hamad A, 2004, "The relationship between marriage, divorce and migration in a British data set" Journal of Ethnic and Migration Studies 30 339-351

Hsiao C, 2003 Analysis of Panel Data (Second Edition) (Cambridge University Press, Cambridge)

Kan K, 1999, "Expected and unexpected residential mobility" Journal of Urban Economics 45 72-96 
Kleinhans R, 2009, “Does social capital affect residents' propensity to move from restructured neighbourhoods?" Housing Studies 24 629-651

Kley S, Mulder C, 2010, "Considering, planning, and realizing migration in early adulthood. The influence of life-course events and perceived opportunities on leaving the city in Germany" Journal of Housing and the Built Environment 25 73-94

Kley S, 2010, "Explaining the stages of migration within a life-course framework." European Sociological Review Advance Access (published online May 23 ${ }^{\text {rd }}, 2010$ ) doi:10.1093/esr/jcq020

Landale N S, Guest A M, 1985, "Constraints, satisfaction and residential mobility: Speare's model reconsidered" Demography 22 199-222

Lu M, 1998, "Analyzing migration decisionmaking: relationships between residential satisfaction, mobility intentions, and moving behavior" Environment and Planning $A$ $301473-1495$

Lu M, 1999a, "Do people move when they say they will? Inconsistencies in individual migration behavior" Population \& Environment 20 467-488

Lu M, 1999b, "Determinants of residential satisfaction: ordered logit vs regression models" Growth and Change 30 264-287 
McHugh K E, 1984, "Explaining migration intentions and destination selection" The Professional Geographer 36315 - 325

Molin E, Oppewal H, Timmermans H, 1996, "Predicting consumer response to new housing: A stated choice experiment." Journal of Housing and the Built Environment $11297-311$

Morris E W, Winter M, 1975, "A theory of family housing adjustment" Journal of Marriage and Family 37 79-88

Morris E W, Crull S R, Winter M, 1976, "Housing norms, housing satisfaction and the propensity to move" Journal of Marriage and Family 38 309-320

Mulder C, Hooimeijer P, 1999, "Residential relocations in the life course", in Population Issues: An Interdisciplinary Focus, Eds L van Wissen, P Dykstra (Plenum Press, New York) pp 159-186

Rossi P H, 1955 Why Families Move: A Study in the Social Psychology of Urban Residential Mobility (Free Press, Glencoe)

Sell R, De Jong G F, 1983, "Deciding whether to move: mobility, wishful thinking and adjustment" Sociology and Social Research 67 146-165 
Sirgy M, Grzeskowiak S, Su C, 2005, "Explaining housing preference and choice: The role of self-congruity and functional congruity" Journal of Housing and the Built Environment 20 329-347

Speare A, 1974, "Residential satisfaction as an intervening variable in residential mobility" Demography 11 173-188

Speare A, Goldstein S, Frey W, 1975 Residential Mobility, Migration, and Metropolitan Change (Ballinger Publishing Co, Cambridge)

Taylor, M F (Ed.) with Brice J, Buck N, Prentice-Lane E, 2010 British Household Panel Survey User Manual Volume A: Introduction, Technical Report and Appendices (University of Essex, Colchester)

van Arsdol Jr M, Sabagh G, Butler E, 1968, "Retrospective and subsequent metropolitan residential mobility" Demography 5 249-267

van Ham M, Mulder C H, Hooimeijer P, 2001, "Spatial flexibility in job mobility: macro-level opportunities and micro-level restrictions" Environment and Planning A $33921-940$

van Ham M, Feijten P, 2008, "Who wants to leave the neighbourhood? The effect of being different from the neighbourhood population on wishes to move" Environment and Planning A 40 1151-1170 
Wolpert J, 1965, "Behavioral aspects of the decision to migrate" Papers in Regional Science 15 159-169

Wooldridge J M, 2002 Econometric Analysis of Cross Section and Panel Data (MIT Press, London) 
Table 1. Variable summary statistics (total $n=63,083$ )

\begin{tabular}{|c|c|c|}
\hline Categorical variables & $\mathrm{N}$ & $\%$ \\
\hline \multicolumn{3}{|c|}{ Moving desire-expectation combinations (ref=no desire or expectation) } \\
\hline Desire but no expectation & 13,450 & 21.32 \\
\hline No desire but expectation & 2,181 & 3.46 \\
\hline Desire and expectation & 4,883 & 7.74 \\
\hline Mover (ref=no move) & 6,669 & 10.57 \\
\hline Dissatisfied with dwelling (ref=satisfied) & 14,212 & 22.53 \\
\hline Dislike neighbourhood (ref=like neighbourhood) & 4,410 & 6.99 \\
\hline Female $(r e f=m a l e)$ & 37,274 & 59.09 \\
\hline Ethnic minority (ref=white) & 1,495 & 2.37 \\
\hline \multicolumn{3}{|c|}{ Lagged partner status change $t-1$ to $t$ (ref=remained couple) ${ }^{1}$} \\
\hline Remained single & 20,498 & 32.49 \\
\hline Formed partnership & 1,353 & 2.14 \\
\hline Partnership dissolution/widowhood & 1,517 & 2.40 \\
\hline Unknown-single & 2,232 & 3.54 \\
\hline Unknown-couple & 2,609 & 4.14 \\
\hline \multicolumn{3}{|c|}{ Lagged change in presence of children $t-1$ to $t$ (ref=remained without children) ${ }^{1}$} \\
\hline Children-same number & 15,030 & 23.83 \\
\hline Increase in number of children & 1,919 & 3.04 \\
\hline Decrease in number of children & 2,617 & 4.15 \\
\hline Unknown-no children & 3,540 & 5.61 \\
\hline Unknown-children & 1,292 & 2.05 \\
\hline \multicolumn{3}{|l|}{ Education level (ref=no formal education) } \\
\hline Low (basic secondary school level) & 14,879 & 23.59 \\
\hline Medium (higher school/vocational equivalent) & 22,859 & 36.24 \\
\hline High (degree+) & 8,481 & 13.44 \\
\hline Unknown & 1,226 & 1.94 \\
\hline \multicolumn{3}{|c|}{ Lagged employment status change $t-1$ to $t$ (ref=remained employed) ${ }^{1}$} \\
\hline Remained unemployed & 539 & 0.85 \\
\hline Remained outside labour force & 21,297 & 33.76 \\
\hline Entered employment & 1,778 & 2.82 \\
\hline Entered unemployment & 894 & 1.42 \\
\hline Exited labour force & 2,086 & 3.31 \\
\hline Unknown-employed & 2,741 & 4.35 \\
\hline Unknown-unemployed & 263 & 0.42 \\
\hline Unknown-outside labour force & 2,088 & 3.31 \\
\hline \multicolumn{3}{|l|}{ Housing tenure (ref=homeowner) } \\
\hline Social renter & 12,381 & 19.63 \\
\hline Private renter & 6,651 & 10.54 \\
\hline \multicolumn{3}{|l|}{ Years in dwelling (ref $=0-1)$} \\
\hline $2-5$ & 10,678 & 16.93 \\
\hline $6-20$ & 12,555 & 19.90 \\
\hline $21-40$ & 5,605 & 8.89 \\
\hline$>40$ & 1,537 & 2.44 \\
\hline Unknown & 22,537 & 35.73 \\
\hline Continuous variables & Mean & Standard deviation \\
\hline Age & 49.17 & 17.50 \\
\hline $\mathrm{Age}^{2}$ & 2723.81 & 1839.01 \\
\hline Real household income $(£ 10,000)$ & 2.73 & 2.32 \\
\hline Roomstress & 0.59 & 0.31 \\
\hline
\end{tabular}


Table 2. Hypothesised variable effects on moving desire-expectation combinations and actual moves

\begin{tabular}{|c|c|c|c|c|}
\hline \multirow[b]{2}{*}{ Variables } & \multicolumn{3}{|c|}{ Moving desire-expectation combination } & \multirow[b]{2}{*}{$\begin{array}{l}\text { Actual } \\
\text { mobility }\end{array}$} \\
\hline & $\begin{array}{l}\text { Desire, no } \\
\text { expectation }\end{array}$ & $\begin{array}{l}\text { Expectation, } \\
\text { no desire }\end{array}$ & $\begin{array}{l}\text { Desire and } \\
\text { expectation }\end{array}$ & \\
\hline Dissatisfaction & + & 0 & + & + \\
\hline Age & - & - & - & - \\
\hline Ethnic minority & + & + & - & 0 \\
\hline Union formation & + & 0 & + & + \\
\hline Union dissolution/widowhood & 0 & + & + & + \\
\hline Increased number of children & + & 0 & + & + \\
\hline Unemployed & + & + & 0 & + \\
\hline Education & - & 0 & + & + \\
\hline Income & - & - & + & + \\
\hline Social renter & + & 0 & 0 & 0 \\
\hline Private renter & - & + & + & + \\
\hline Roomstress & + & 0 & + & + \\
\hline Duration of stay & - & - & - & - \\
\hline Desire no expectation & & & & + \\
\hline Expectation no desire & & & & ++ \\
\hline Desire and expectation & & & & +++ \\
\hline
\end{tabular}


Figure 1. Moving desire-expectation combinations and actual moves by age

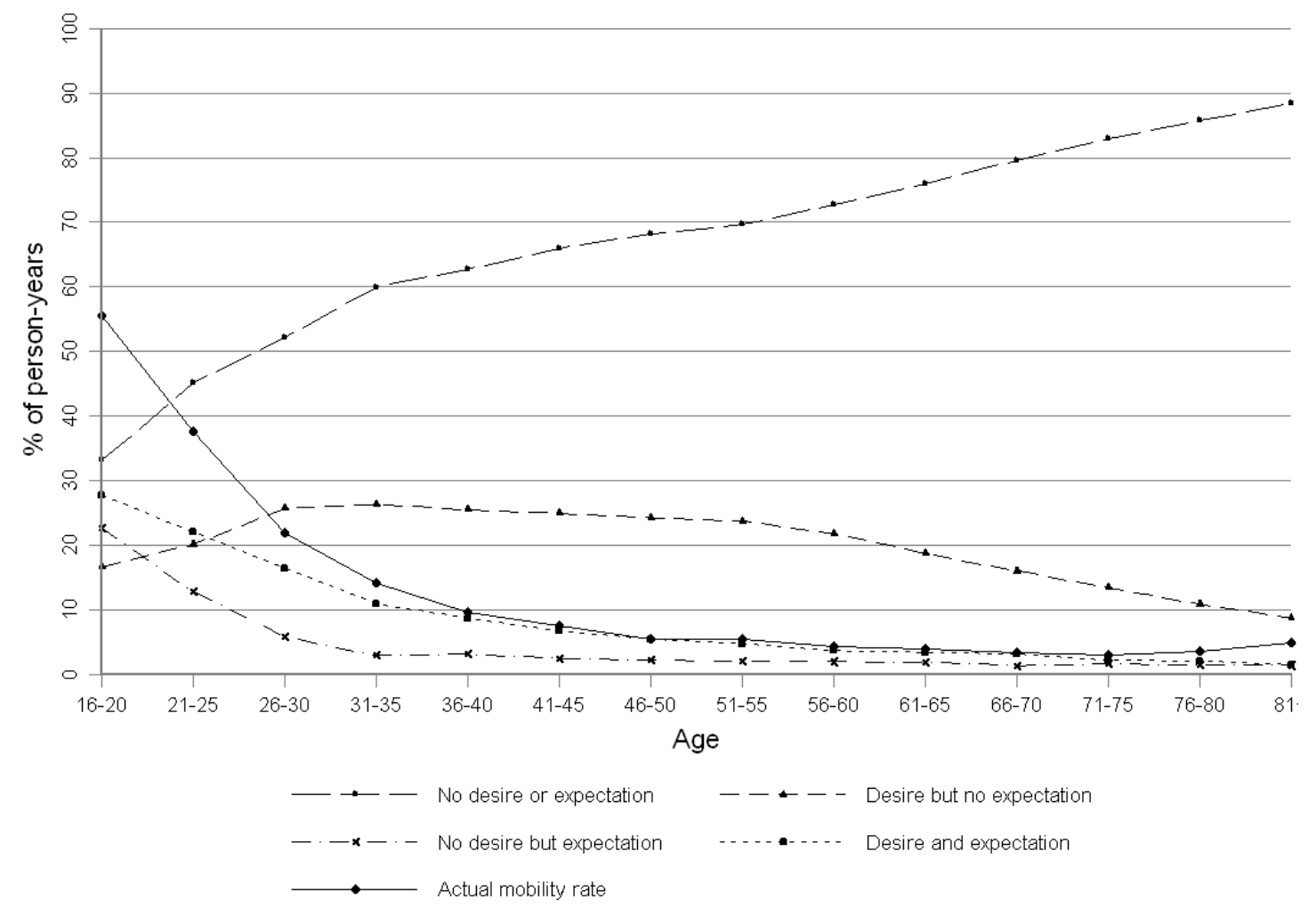


Table 3. Bivariate analysis linking subjective evaluations of dwelling and neighbourhood to moving desire-expectation combinations

Respondent's desire-expectation combination at wave $t$

\begin{tabular}{|c|c|c|c|c|}
\hline $\begin{array}{l}\text { No desire or } \\
\text { expectation }\end{array}$ & $\begin{array}{c}\text { Desire, no } \\
\text { expectation }\end{array}$ & $\begin{array}{l}\text { No desire, } \\
\text { expectation }\end{array}$ & $\begin{array}{l}\text { Desire and } \\
\text { expectation }\end{array}$ & $\begin{array}{c}\text { Total } \\
(100 \% \text { and } N)\end{array}$ \\
\hline
\end{tabular}

\begin{tabular}{|c|c|c|c|c|c|}
\hline \multicolumn{6}{|c|}{ Housing satisfaction (\%) } \\
\hline Satisfied & 76.12 & 16.20 & 3.33 & 4.35 & 48,871 \\
\hline Dissatisfied & 37.77 & 38.94 & 3.90 & 19.39 & 14,212 \\
\hline \multicolumn{6}{|c|}{ Liking the neighbourhood (\%) } \\
\hline Likes & 72.04 & 18.27 & 3.68 & 6.00 & 58,673 \\
\hline Dislikes & 6.83 & 61.86 & 0.43 & 30.88 & 4,410 \\
\hline Total (\% and $\mathrm{N})$ & $\begin{array}{c}42,569 \\
67.48\end{array}$ & $\begin{array}{c}13,450 \\
21.32\end{array}$ & $\begin{array}{c}2,181 \\
3.46\end{array}$ & $\begin{array}{c}4,883 \\
7.74\end{array}$ & $\begin{array}{l}63,083 \\
100.00\end{array}$ \\
\hline
\end{tabular}

Source: BHPS (own calculations) 
Table 4. Multinomial logit model of moving desire-expectation combinations ( $r$ ef=no desire or expectation)

\begin{tabular}{|c|c|c|c|c|c|c|}
\hline \multirow[t]{2}{*}{ Variable } & \multicolumn{2}{|c|}{ Desire, no expectation } & \multicolumn{2}{|c|}{ Expectation, no desire } & \multicolumn{2}{|c|}{ Desire and expectation } \\
\hline & Coeff. & S.E. & Coeff. & S.E. & Coeff. & S.E. \\
\hline Dissatisfied with dwelling & $1.201^{\star * *}$ & 0.032 & $0.514^{\star \star \star}$ & 0.057 & $1.643^{* * *}$ & 0.041 \\
\hline Dislike neighbourhood & $3.347^{* * *}$ & 0.073 & 0.287 & 0.242 & $3.843^{* * *}$ & 0.082 \\
\hline Age & $0.015^{\star *}$ & 0.007 & $-0.090^{* * *}$ & 0.009 & $-0.059^{\star * *}$ & 0.009 \\
\hline $\mathrm{Age}^{2}$ & $-0.000^{* * *}$ & 0.000 & $0.001^{* * *}$ & 0.000 & $0.000 * *$ & 0.000 \\
\hline Female & -0.070 & 0.037 & $-0.200^{\star * *}$ & 0.053 & $-0.107^{\star *}$ & 0.046 \\
\hline Ethnic minority & $0.216^{\star *}$ & 0.107 & 0.088 & 0.152 & -0.065 & 0.145 \\
\hline \multicolumn{7}{|c|}{ Partner status change $t-1$ to $t$ (ref=remained couple $)^{1}$} \\
\hline Remained single & $-0.106^{* *}$ & 0.046 & $0.437^{* * *}$ & 0.069 & $0.143^{\star *}$ & 0.058 \\
\hline Formed partnership & $0.167^{* *}$ & 0.08 & 0.120 & 0.132 & $0.410^{\star * *}$ & 0.094 \\
\hline Partnership dissolution/widowhood & 0.051 & 0.078 & $1.083^{* * *}$ & 0.121 & $0.760^{\star \star *}$ & 0.097 \\
\hline \multicolumn{7}{|c|}{ 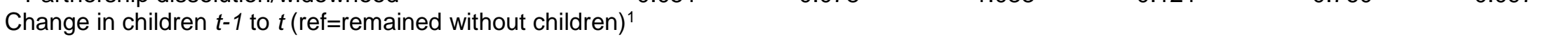 } \\
\hline Children-same number & $-0.241^{\star \star \star}$ & 0.046 & $-0.558^{* * *}$ & 0.08 & $-0.476^{\star \star \star}$ & 0.059 \\
\hline Increased number of children & $-0.213^{\star *}$ & 0.072 & $-0.447^{\star *}$ & 0.142 & $-0.216^{\star *}$ & 0.089 \\
\hline Decreased number of children & $-0.331^{\star \star \star}$ & 0.064 & -0.175 & 0.109 & $-0.352^{* \star *}$ & 0.087 \\
\hline \multicolumn{7}{|l|}{ Education level (ref=very low) } \\
\hline Low & $0.117^{* *}$ & 0.054 & -0.130 & 0.093 & $0.219^{* *}$ & 0.078 \\
\hline Medium & $0.200^{\star * *}$ & 0.053 & 0.086 & 0.089 & $0.433^{\star * *}$ & 0.075 \\
\hline High & $0.154^{\star *}$ & 0.069 & $0.429^{* * *}$ & 0.101 & $0.721^{* * *}$ & 0.088 \\
\hline Unknown & 0.132 & 0.131 & -0.285 & 0.209 & $0.337^{\star \star}$ & 0.165 \\
\hline \multicolumn{7}{|c|}{ 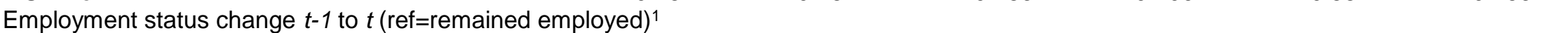 } \\
\hline Remained unemployed & -0.208 & 0.146 & 0.027 & 0.256 & -0.011 & 0.196 \\
\hline Remained out of labour force & $-0.342^{\star * *}$ & 0.050 & $0.268^{* * *}$ & 0.078 & $-0.145^{\star *}$ & 0.067 \\
\hline Entered employment & -0.053 & 0.068 & 0.135 & 0.120 & 0.051 & 0.089 \\
\hline Entered unemployment & -0.131 & 0.098 & $0.585^{\star * *}$ & 0.163 & $0.250^{* *}$ & 0.123 \\
\hline Exited labour force & $-0.223^{\star \star \star}$ & 0.067 & 0.161 & 0.135 & $0.225^{\star *}$ & 0.093 \\
\hline Real household income $(£ 10,000)$ & $-0.073^{\star \star \star}$ & 0.010 & 0.001 & 0.011 & 0.005 & 0.008 \\
\hline \multicolumn{7}{|l|}{ Housing tenure (ref=homeowner) } \\
\hline Social renter & $0.109^{* *}$ & 0.049 & -0.132 & 0.087 & $-0.155^{\star *}$ & 0.065 \\
\hline Private renter & $0.130^{* *}$ & 0.062 & $1.260^{* * *}$ & 0.069 & $1.024^{* * *}$ & 0.063 \\
\hline Roomstress & $0.419^{* * *}$ & 0.065 & $0.387^{* * *}$ & 0.095 & $0.489^{* * *}$ & 0.077 \\
\hline \multicolumn{7}{|l|}{ Years in dwelling } \\
\hline $2-5$ & $0.537^{\star \star *}$ & 0.044 & -0.055 & 0.076 & $0.248^{\star \star *}$ & 0.059 \\
\hline $6-20$ & $0.731^{\star \star *}$ & 0.056 & 0.000 & 0.095 & $0.272^{\star \star \star}$ & 0.077 \\
\hline $21-40$ & $0.809^{\star \star \star}$ & 0.078 & -0.146 & 0.143 & -0.196 & 0.136 \\
\hline$>40$ & $0.683^{\star * *}$ & 0.155 & $-0.721^{\star *}$ & 0.314 & -0.054 & 0.264 \\
\hline Unknown & $0.460^{\star * *}$ & 0.050 & -0.133 & 0.074 & 0.000 & 0.066 \\
\hline Constant & $-1.910^{* * *}$ & 0.178 & $-0.814^{\star *}$ & 0.248 & $-1.575^{\star \star *}$ & 0.221 \\
\hline \multicolumn{3}{|c|}{$\begin{array}{l}\text { Model log pseudolikelihood=46,531.09(improvement over null=10,831.396) } \\
\text { Standard errors adjusted for } 14,506 \text { clusters within personal identification number }\end{array}$} & \multicolumn{2}{|c|}{$\begin{array}{l}\text { Wald } \text { chi }^{2}(\text { d.f. })=9961.82(111) \\
{ }^{* * *}=p<0.001 \\
{ }^{* *}=p<0.05\end{array}$} & \multicolumn{2}{|c|}{$\begin{array}{l}\text { Pseudo } r^{2}=0.189 \\
N=63,083\end{array}$} \\
\hline
\end{tabular}

Source: BHPS (own calculations) ${ }^{1}$ These variables also contain dummies for transitions where the individual's status at $t-1$ was unknown (results not shown here) 
Table 5. Moving desire-expectation combinations and actual moving behaviour over the next year

\begin{tabular}{lccc}
\hline & \multicolumn{2}{c}{$\begin{array}{c}\text { Respondent's actual moving behaviour } \\
\text { between } t \text { and } t+1\end{array}$} & \\
\cline { 2 - 3 } $\begin{array}{l}\text { Respondent's desire-expectation } \\
\text { category at wave } t(\%)\end{array}$ & Stayer & Mover & Total $(100 \%$ and N) \\
\hline No desire or expectation & 95.62 & 4.38 & 42,569 \\
Desire but no expectation & 92.00 & 8.00 & 13,450 \\
No desire but expectation & 51.90 & 48.10 & 2,181 \\
Desire and expectation & 45.14 & 54.86 & 4,883 \\
\hline Total $(\%$ and N) & 89.43 & 10.57 & 100.00 \\
\hline
\end{tabular}

Source: BHPS (own calculations) 
Table 6. Panel logit models of the annual likelihood of moving (ref=no move)

\begin{tabular}{|c|c|c|c|c|}
\hline \multirow[t]{2}{*}{ Variable } & \multicolumn{2}{|l|}{ Model 1} & \multicolumn{2}{|l|}{ Model 2} \\
\hline & Coeff. & S.E. & Coeff. & S.E. \\
\hline Age & $-0.105^{\star \star *}$ & 0.006 & $-0.091^{\star \star *}$ & 0.007 \\
\hline $\mathrm{Age}^{2}$ & $0.001^{* * *}$ & 0.000 & $0.001^{* * *}$ & 0.000 \\
\hline Female & $-0.146^{* *}$ & 0.034 & $-0.111^{* *}$ & 0.037 \\
\hline Ethnic minority & -0.192 & 0.102 & -0.147 & 0.111 \\
\hline \multicolumn{5}{|l|}{$\begin{array}{l}\text { Partner status change } t \text { to } t+1^{1} \\
\text { (ref=remained couple) }\end{array}$} \\
\hline Remained single & $0.195^{\star * *}$ & 0.044 & $0.144^{* *}$ & 0.048 \\
\hline Formed partnership & $1.742^{\star \star *}$ & 0.077 & $1.621^{* * *}$ & 0.085 \\
\hline Partnership dissolution/widowhood & $1.764^{\star \star \star}$ & 0.076 & $1.905^{\star \star \star}$ & 0.082 \\
\hline \multicolumn{5}{|l|}{$\begin{array}{l}\text { Change in n. children } t \text { to } t+1^{1} \\
\text { (ref=remained without children) }\end{array}$} \\
\hline Children-same number & $-0.234^{* * *}$ & 0.047 & $-0.116^{\star *}$ & 0.051 \\
\hline Increased number of children & $0.312^{\star * \star}$ & 0.072 & $0.310^{\star \star *}$ & 0.081 \\
\hline Decreased number of children & 0.015 & 0.088 & 0.167 & 0.095 \\
\hline \multicolumn{5}{|l|}{ Education level (ref=very low) } \\
\hline Low & 0.077 & 0.057 & 0.022 & 0.060 \\
\hline Medium & $0.182^{\star \star \star}$ & 0.055 & 0.045 & 0.058 \\
\hline High & $0.420^{* * *}$ & 0.065 & $0.153^{* *}$ & 0.071 \\
\hline Unknown & -0.161 & 0.126 & $-0.313^{* \star}$ & 0.139 \\
\hline \multicolumn{5}{|l|}{$\begin{array}{l}\text { Employment status change } t \text { to } t+1^{1} \\
\text { (ref=remained employed) }\end{array}$} \\
\hline Remained unemployed & 0.029 & 0.165 & 0.057 & 0.179 \\
\hline Remained outside labour force & 0.056 & 0.051 & 0.074 & 0.055 \\
\hline Entered employment & $0.317^{\star \star \star}$ & 0.080 & 0.172 & 0.090 \\
\hline Entered unemployment & $0.304^{* *}$ & 0.112 & 0.238 & 0.124 \\
\hline Exited labour force & $0.347^{\star \star \star}$ & 0.084 & $0.249^{* *}$ & 0.091 \\
\hline Real household income $(£ 10,000)$ & $0.016^{* *}$ & 0.007 & 0.013 & 0.008 \\
\hline \multicolumn{5}{|l|}{ Housing tenure(ref=homeowner) } \\
\hline Social renter & $-0.134^{* *}$ & 0.051 & -0.103 & 0.055 \\
\hline Private renter & $1.236^{\star \star \star}$ & 0.047 & $0.905^{\star \star \star}$ & 0.052 \\
\hline Roomstress & $0.246^{\star \star \star}$ & 0.061 & 0.097 & 0.066 \\
\hline \multicolumn{5}{|l|}{ Years in dwelling $(r e f=0-1)$} \\
\hline $2-5$ & $-0.178^{\star \star *}$ & 0.048 & $-0.243^{\star \star *}$ & 0.052 \\
\hline $6-20$ & $-0.346^{* * *}$ & 0.063 & $-0.462^{* * *}$ & 0.066 \\
\hline $21-40$ & $-0.751^{\star \star \star}$ & 0.100 & $-0.776^{\star * *}$ & 0.104 \\
\hline$>40$ & $-0.760^{* \star *}$ & 0.175 & $-0.782^{\star \star \star}$ & 0.179 \\
\hline Unknown & $-0.661^{* \star *}$ & 0.051 & $-0.735^{\star \star \star}$ & 0.054 \\
\hline Dissatisfied with dwelling & $0.685^{\star \star \star}$ & 0.036 & $0.246^{\star * *}$ & 0.041 \\
\hline Dislike neighbourhood & $0.730^{\star \star \star}$ & 0.052 & 0.021 & 0.059 \\
\hline \multicolumn{5}{|l|}{$\begin{array}{l}\text { Moving desire-expectation } \\
\text { (ref=no desire or expectation) }\end{array}$} \\
\hline Desire but no expectation & & & $0.543^{* * *}$ & 0.048 \\
\hline Expectation but no desire & & & $2.223^{\star \star \star}$ & 0.065 \\
\hline Desire and expectation & & & $2.905^{\star * *}$ & 0.054 \\
\hline Intercept & -0.214 & 0.159 & $-1.003^{* \star *}$ & 0.173 \\
\hline Rho & 0.077 & 0.012 & 0.085 & 0.014 \\
\hline Log likelihood(improvement over null) & \multicolumn{2}{|c|}{$-15,425.062(4,856.717)$} & \multicolumn{2}{|c|}{$-13,280.462(7,001.317)$} \\
\hline Wald chi ${ }^{2}$ (d.f.) & \multicolumn{2}{|c|}{$6,865.983(37)$} & \multicolumn{2}{|c|}{$7,221.828(40)$} \\
\hline $\mathrm{N}$ & \multicolumn{2}{|c|}{63,083} & \multicolumn{2}{|c|}{63,083} \\
\hline
\end{tabular}

Source: BHPS (own calculations) $\quad{ }^{* \star *}=p<0.001^{* *}=p<0.05$

1 These variables also contain dummies for transitions where the individual's status at $t+1$ was unknown (results not shown here) 